\title{
Modelizando el territorio metropolitano del futuro. Cálculo de potenciales urbanísticos en la metrópolis de Barcelona
}

\author{
Pere Manubens Gil ${ }^{1}$ | Laura Bertran Merlo ${ }^{2}$ | Judith Recio Heredia ${ }^{3}$ | Alexandra Quesada Serrano ${ }^{4}$ | \\ Xavier Alarcón Carbó ${ }^{5}$
}

Recibido: 22-11-2020 | en su versión final: 22-02-2021

Resumen

\begin{abstract}
El Plan General Metropolitano (PGM) ha sido una referencia de modelo urbano operacional y es la base del planeamiento vigente. El Área Metropolitana de Barcelona (AMB) está actualmente redactando el Plan Director Urbanístico metropolitano (PDU). Este plan revisará los elementos estructurales del PGM que han quedado desfasados debido a su antigüedad. El objetivo principal de esta comunicación es mostrar como el PDU afronta la evolución de los modelos urbanos operacionales. Dicha evolución viene determinada por dos factores. Primero, la asunción de los retos de desarrollo urbano orientado a la transformación de la ciudad construida, sin ocupar nuevos suelos. Segundo, la irrupción de las nuevas tecnologías de simulación, que requiere de bases de datos específicas para el urbanismo y la planificación, en las que se modelicen las formas urbanas. Estos dos factores están íntimamente relacionados: la disponibilidad de datos con un alto nivel de desagregación permite adaptar los modelos operacionales a contextos urbanos específicos. También facilita monitorizar los parámetros del modelo. Como consecuencia, el nuevo modelo operacional se convierte en una herramienta dinámica de gran utilidad para la modulación de diferentes escenarios de desarrollo urbanístico y para una evaluación continuada de las estrategias urbanas. La metodología de cálculo del potencial de crecimiento urbano desarrollada por el equipo de redacción del PDU pretende ejemplificar la evolución de los modelos urbanos operacionales. La novedad reside en el detalle de la modelización de las formas urbanas, tanto en la ciudad existente como en la ciudad planeada, y las posibilidades de simulación que ofrece.
\end{abstract}

Palabras clave: Modelo; datos; simulación; potencial

Citación

Manubens Gil, P. et al. (2021). Modelizando el territorio metropolitano del futuro. Cálculo de potenciales urbanísticos en la metrópolis de Barcelona. ACE: Architecture, City and Environment, 16(46), 9883. DOI: http://dx.doi.org/10.5821/ace.16.46.9883

\section{Modelling the Future Metropolitan Territory. To Calculate Urban Development Potential in Barcelona Metropolitan Area}

Abstract

\begin{abstract}
The Barcelona Metropolitan Urban Plan (PGM) from 1976 was based on operational urban models. The PGM still is the main metropolitan regulation framework. However, the Metropolitan Area of Barcelona (AMB) is currently drafting the new Metropolitan Master Plan (PDU), which will update key structural elements of PGM that are outdated. The aim of this work is to detail how the PDU is evolving the operational urban models from PGM. This is analysed in two specific directions. On the one hand, the change of the urban objectives: in the 1970s PGM aimed at accommodating and regulating urban growth whereas nowadays we are dealing with the transformation and regeneration of existing fabrics. On the other hand, the obvious evolution of scientific knowledge and technological state of the art. These two factors are closely related. The availability of detailed and disaggregated databases allows to apply the operational models to specific urban areas. Also, it allows better tracking and monitoring of certain key urban parameters. This dynamic characteristic becomes especially useful to model different urban development scenarios and to evaluate urban strategies. Finally, in this paper, we present a methodology to calculate the urban potential development as an application of the operational urban models' evolution. The methodology is characterized by detailed urban form modelling techniques from both the existing and planned city. This new approach opens the door to the evaluation of many urban scenarios.
\end{abstract}

Keywords: Models; database; simulation; potential

${ }^{1}$ Arquitecto, AMB. ${ }^{2}$ Arquitecta, AMB. ${ }^{3}$ Arquitecta, AMB. ${ }^{4}$ Arquitecta, AMB. ${ }^{5}$ Arquitecto, AMB. Correo de contacto: jacarbo@amb.cat

ACE, 16 (46) CC BY-ND 3.0 ES | UPC Barcelona, España | Modelizando en territorio metropolitano del futuro. 


\section{Introducción}

El área metropolitana de Barcelona ${ }^{1}$ es un territorio de poco más de $600 \mathrm{~km}^{2}$ en el que viven 3,2 millones de habitantes y engloba 36 municipios. La orografía de este territorio limita su expansión y provoca constantemente cierta tensión entre los requerimientos de la sociedad y la capacidad del territorio para acoger nuevos usos urbanos.

El desarrollo y la transformación urbanística reciente de este territorio se ha realizado siguiendo las determinaciones del Plan General Metropolitano (PGM) aprobado en el año 1976. En el transcurso de los 44 años desde su aprobación, y con el objetivo de adaptarlo a las necesidades cambiantes de la sociedad, el PGM ha sido modificado de manera puntual más de 1.500 veces. Muchas de estas modificaciones han ido en detrimento de una visión conjunta de la metrópoli, necesaria para la funcionalidad, sostenibilidad y resiliencia de este territorio.

Cada vez se hace más evidente la necesidad de dotar de una nueva estructura a este territorio, que recupere la visión conjunta y resuelva el desgaste de las figuras de planeamiento urbanístico, que no son capaces de responder a los nuevos retos y necesidades de la metrópolis actual.

La baja natalidad y envejecimiento de la población, las nuevas formas de movilidad, la irrupción de las nuevas tecnologías y sus implicaciones sociales y económicas, las demandas sociales en materia de información, vivienda asequible y dotaciones socioambientales de calidad, así como los nuevos retos ambientales, suponen nuevas demandas al planeamiento y por lo tanto un nuevo enfoque tanto en el análisis de la realidad existente como en el desarrollo de las nuevas propuestas.

Para dar respuesta a estas nuevas demandas, el Àrea Metropolitana de Barcelona (AMB) está redactando el Plan Director Urbanístico metropolitano² (PDU). En marzo de 2019 se aprobó el avance del plan y actualmente se está redactando el documento inicial. El objetivo del PDU es dotar al territorio de una estructura metropolitana y un marco urbanístico común acordes con la realidad social, económica y ambiental del momento.

Ante el reto de planificar una metrópolis consolidada, compleja, diversa y dinámica, y aprovechando el potencial de los medios tecnológicos actuales, el PDU se propone hacer uso de los datos e información disponibles con el objetivo de desarrollar modelos descriptivos para la comprensión de la realidad existente y modelos exploratorios para la simulación de los nuevos crecimientos, que permitan evaluar cómo se ajustan a las capacidades del territorio desde el punto de vista social, ambiental y de movilidad.

Con esta finalidad, el AMB ha realizado un esfuerzo por parametrizar los elementos esenciales que definen la forma urbana y los usos característicos de nuestras ciudades: sistemas de ordenación, volumetrías, edificabilidad por usos, etc.

La parametrización de estos elementos se ha realizado a dos niveles: la ciudad existente y la ciudad planeada. Todo ello ha implicado un trabajo intensivo de explotación de bases de datos existentes y la creación de nuevas bases de datos, como veremos posteriormente.

\footnotetext{
1 Este artículo utiliza el término "área metropolitana de Barcelona" para referirse al territorio metropolitano, y el término "AMB" para referirse a la administración pública homónima que gestiona y tiene competencias sobre dicho territorio. Ver www.amb.cat para más información.

2 Para más información sobre el plan, se puede consultar https://urbanisme.amb.cat
} 
El propósito de esta comunicación es mostrar las características de alguna de estas bases de datos, cómo el PDU está haciendo uso de ellas y apuntar, con un ejemplo, algunos de los avances que se están considerando para actualizar el concepto de modelo operacional y modelo exploratorio aplicado al planeamiento urbanístico.

Este artículo se estructura en 4 secciones. La primera sección se corresponde con la presente introducción. La segunda contextualiza el concepto de modelo que se va a tener en cuenta en el artículo y aquellos aspectos del PGM, de la base de datos llamada "refundido de planeamiento" y del propio PDU necesarios para contextualizar el objeto de la comunicación. La sección tercera describe la herramienta de cálculo del potencial de crecimiento urbano. Esta herramienta es el ejemplo que pretende dar luz sobre los avances que se están considerando en el concepto de modelo operacional y modelo exploratorio. Finalmente, la última sección pretende explicitar dichos avances a modo de conclusión.

\section{Contextualización del concepto de modelización urbana}

Este artículo toma como punto de partida la definición de modelo urbano de David Foot "una abstracción simplificada de un fenómeno del mundo real” (Foot, 1981) y las apreciaciones de Gustavo Munizaga "... En la construcción del modelo hay un proceso necesario de selección y otro de abstracción y representación” (Munizaga, 2014).

Marcial Echeñique (1970) establece una tipología de modelos con respecto a la función. Según este autor, hay cuatro tipos de modelos: los modelos descriptivos, que se orientan a la observación y comprensión de la realidad; los modelos predictivos, cuya intención principal es predecir el futuro; los modelos exploratorios, en que se extrapolan y varían los parámetros básicos de la realidad observada, para formular o descubrir otras realidades; y los modelos de planificación, en los que, con objetivos operacionales, se determinan criterios de optimización sobre los medios para lograr los objetivos o programas preestablecidos sobre una determinada realidad.

Desde la implantación generalizada de las tecnologías de la información se han venido desarrollando gran cantidad de modelos orientados al estudio de la ciudad y el territorio, centrados en aspectos parciales, o con visión más global y que utilizan, a veces, metodologías distintas. Desde modelos que se basan en el estudio de patrones de ocupación del suelo teniendo en cuenta distintos factores: accesibilidad, ambientales, económicos, de planeamiento, o sociales; hasta modelos con objetivos netamente operacionales y de planificación urbanística.

En cuanto a los primeros, cabe destacar en el contexto de la metrópolis de Barcelona, el caso de Evalúamet, un modelo que en primera instancia tiene el objetivo de evaluar la situación base de eficiencia del sistema metropolitano de Barcelona y, posteriormente, aplicar el modelo en fase predictiva para evaluar distintos planes de infraestructura, transporte y ordenamiento territorial, y su impacto bajo un enfoque de sostenibilidad (económica, social y ambiental) de los sistemas metropolitanos. Este modelo conceptual surge con la premisa de la integración funcional de los procedimientos, más que con la exactitud o complejidad de los últimos desarrollos científicos en cada tema (Cerda et al., 2012). Otro ejemplo relevante es el simulador propuesto por la Agencia de Ecología Urbana de Barcelona (SIMU). Estos modelos exploratorios incluyen propuestas de planeamiento (ya sean propuestas de infraestructuras o de ocupación del suelo), como un factor de interacción con el modelo, pero no pretenden alterar la filosofía del modelo exploratorio a un modelo de carácter más operacional.

ACE, 16 (46) CC BY-ND 3.0 ES | UPC Barcelona, España | Modelizando en territorio metropolitano del futuro. 
En cuanto a los segundos, la experiencia más reciente de un modelo de planificación urbanística es el Plan Territorial Metropolitano de Barcelona, pero sin duda el referente más extenso de desarrollo de un modelo de planificación de detalle para la metrópolis de Barcelona es el PGM.

Se trata de un modelo con objetivos operacionales, la finalidad del cual es interactuar con la ciudad existente para corregir situaciones y desarrollar nuevas formas de habitar que permitan dar respuesta a una serie de problemáticas o retos de la sociedad. Como veremos, también introdujo ciertos elementos que podrían considerarse ciertamente exploratorios. En el siguiente capítulo se destacan aquellos elementos del PGM claves para el objeto de esta comunicación.

\subsection{El PGM: las bases de un modelo exploratorio y de planificación}

El PGM de 1976 es fruto de una larga reflexión que se inició en 1964 para abordar la revisión del Plan de ordenación de Barcelona y su zona de influencia de 1953. Esta reflexión se desarrolló principalmente durante la elaboración del Plan Director del Área Metropolitana de Barcelona 1968 ${ }^{3}$ por parte de un equipo pluridisciplinar, durante una época de intenso debate y desarrollo de ideas referentes a la modelización urbana (Solà-Morales, 1969, 1972)

Son varios los retos importantes que afrontó el PGM: desde la escasez de espacios para uso público, hasta unas estructuras viarias existentes inadecuadas para soportar el creciente número de desplazamientos con vehículo privado. El análisis de cómo se abordó cada uno de estos retos daría para desarrollar varios artículos. En este documento nos centraremos en los retos que el PGM afrontó en relación con la forma y la intensidad de uso de los suelos urbanos.

El plan constató una tendencia preocupante a ocupar, con nuevos crecimientos de baja densidad, el poco suelo disponible adecuado para usos urbanos, además de una fuerte especulación en la ciudad central que provocaba una congestión excesiva, con grandes densidades de vivienda que dificultaban una calidad mínima de habitabilidad.

Ante una previsión de crecimiento continuado de la población, el plan desarrolló una serie de mecanismos orientados a limitar las intensidades en suelos centrales y reservar para nuevos crecimientos de intensidad suficiente los escasos suelos disponibles. El modelo planteado evitaba de esta forma el clásico esquema de disminución progresiva de la intensidad conforme se incrementa la distancia al centro.

Partiendo de un análisis detallado de las formas urbanas existentes (Pié, 1997) el plan incluyó una serie de mecanismos de actuación directa sobre el tejido urbano. Estos mecanismos venían definidos mediante una serie de calificaciones y parámetros urbanísticos que establecían unas condiciones concretas en relación con la forma urbana (sistemas de ordenación), la intensidad (edificabilidad y densidad) y los usos.

En relación a la forma urbana se distinguían tres sistemas de ordenación de la edificación (Figura 1).

En la determinación de las intensidades intervenían dos parámetros fundamentales:

- La edificabilidad (superficie de $\mathrm{m}^{2}$ de techo por cada $\mathrm{m}^{2}$ de suelo), que se establecía de forma distinta según el sistema de ordenación de la edificación.

- La densidad (cantidad de viviendas o locales por $\mathrm{m}^{2}$ de suelo), que se establecía mediante un índice para cada una de las calificaciones.

\footnotetext{
3 El Plan Director del Área Metropolitana de Barcelona de 1968 se aprobó únicamente como documento de uso interno.
} 


\section{SISTEMAS DE ORDENACIÓN}

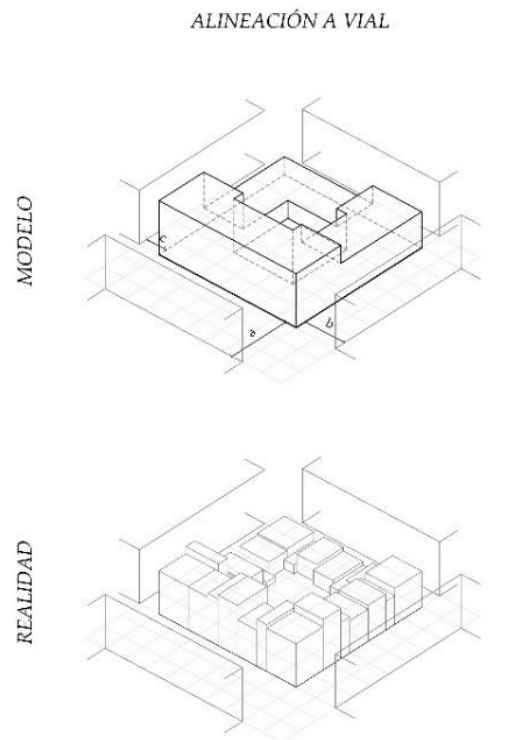

Edificabilidad según ordenación volumétrica: - Profundidad edificable según superficie de la manzin - Altura de la edificación segrin ancho de la calle
EDITICACIÓN AISLADA
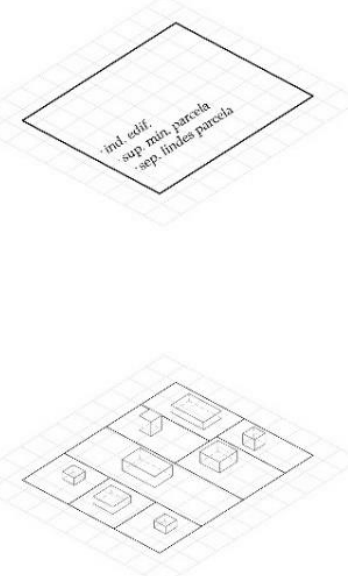

Edificabilidad, superficie minima de parcela y ordenaión volumétrica según calificación urbanistica
VOLUMETRIA ESPECIIICA
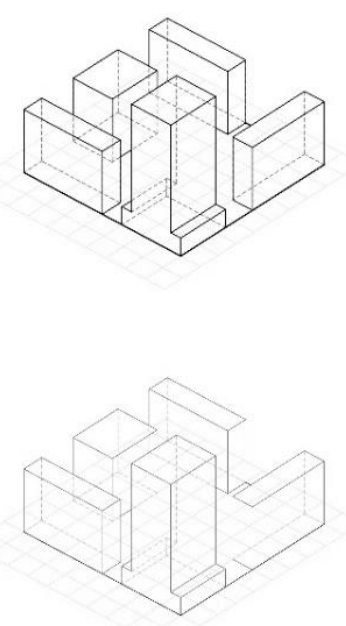

Edificabilidad y ordenaión volumétrice establecidas de forma específica en cada uno de los Planes Parciales

Fuente: Elaboración propia a partir de la información contenida en el Plan General de Ordenación Urbana de la Entidad Municipal Metropolitana de Barcelona. 1976. Memoria del documento de aprobación definitiva, aprobado por la Comisión de Urbanismo de Barcelona, el 14 de julio de 1976.

La edificabilidad de los tejidos urbanos históricos con frentes de edificación alineados a vial (cascos antiguos y ensanches) quedaba determinada por la ordenación volumétrica. Dicha ordenación era la resultante, por un lado, de una profundidad máxima variable en función de la superficie de la manzana sobre la que se encontraban y, por otro lado, de la altura de la edificación que se determinaba en función del ancho de la vía sobre la que daban frente.

La edificabilidad de los tejidos urbanos con edificaciones no alineadas a vial se establecía mediante un índice de edificabilidad para cada una de las calificaciones (Figura 2). Para aquellos tejidos de intensidades bajas y medias se establecían una serie de calificaciones genéricas (edificación aislada). Para determinar la intensidad de los tejidos con intensidades elevadas, se remitía a la ordenación volumétrica específica definida en el documento urbanístico que les dio lugar (Plan Parcial de aprobación anterior al PGM).

Actualmente el PGM continua vigente, por lo que todos estos mecanismos siguen siendo de aplicación. Forman parte del modelo de planificación que propuso el plan. Además, pese a su futura revisión, algunas de estas metodologías seguirán vigentes, pues fueron trasladadas a la Ley del Suelo y la Ley de Urbanismo.

La evaluación del éxito de los objetivos del plan, aunque sería de gran interés, no es el objeto de este artículo. Sin embargo, es interesante describir cómo se aplicaron los mecanismos descritos en el apartado anterior para alcanzar dichos objetivos: este artículo parte de la hipótesis de que algunas de las metodologías de aplicación de estos mecanismos en el plan son un primer ensayo del modelo exploratorio aplicado al planeamiento que el PDU propone desarrollar. 
Figura 2. Parámetros de las distintas zonas previstas por el PGM

\begin{tabular}{|c|c|c|c|c|c|c|c|c|c|}
\hline \multirow[t]{2}{*}{ SISTEMA DE ORDENACIÓ } & \multicolumn{3}{|c|}{ ZONIFICACIÓN } & \multicolumn{2}{|c|}{ INTENSIDAD NETA } & \multicolumn{2}{|c|}{ PARCELA MIN. } & \multicolumn{2}{|c|}{ OCUP. MAX } \\
\hline & & Subzonas & Código & $\begin{array}{l}\text { Edificabilidad } \\
\text { coef. }\end{array}$ & $\begin{array}{c}\text { Densidad } \\
\text { viv/Ha. }\end{array}$ & fachada $m$ & superf. $\mathrm{m} 2$ & $\left.\begin{array}{c}\text { de manzana } \\
{[\%]}\end{array}\right]$ & $\begin{array}{c}\text { de parcela } \\
{[\%]}\end{array}$ \\
\hline \multirow{4}{*}{ ALINEACIÓN A VIAL } & \multirow{2}{*}{ ENSANCHE } & SUB I: INTENSIVA & $13 \mathrm{a}$ & & 350 & 8 & . & 70 & 100 \\
\hline & & SUB II: SEMIINTENSIVA & $13 \mathrm{~b}$ & & 250 & 6,5 & . & 70 & 70 \\
\hline & \multirow{2}{*}{ CASCO ANTIGUO } & $\begin{array}{l}\text { SUB I: SUBSTITUCIÓN DE } \\
\text { LA EDIFICACIÓN ANTIGUA }\end{array}$ & 12 & & 200 & 6,5 & - & 60 & 60 \\
\hline & & $\begin{array}{l}\text { SUB II: CONSERVACIÓN DEL } \\
\text { CENTRO HISTÓRICO }\end{array}$ & $12 \mathrm{~b}$ & & & 6,5 & - & & \\
\hline \multirow{9}{*}{ EDIFICACIÓN AISLADA } & \multirow{5}{*}{ PLURIFAMILIAR } & $\mathrm{V}$ & $20 a / 8$ & 1,5 & \multirow{5}{*}{ edif. / 100} & 15 & 800 & & 30 \\
\hline & & IV & $20 \mathrm{a} / 9$ & 1 & & 14 & 400 & & 10 \\
\hline & & III & $20 \mathrm{a} / 7$ & 0,75 & & 16 & 1000 & & 20 \\
\hline & & II & $20 \mathrm{a} / 5$ & 0,5 & & 20 & 1500 & & 20 \\
\hline & & I & $20 \mathrm{a} / 6$ & 0,25 & & 30 & 2000 & & 15 \\
\hline & \multirow{4}{*}{ UNIFAMILIAR } & VI & $20 \mathrm{a} / 9 \mathrm{u}$ & 1 & \multirow{4}{*}{$\begin{array}{l}1 \text { vivienda por } \\
\text { parcela }\end{array}$} & 14 & 400 & & 40 \\
\hline & & VII & $20 \mathrm{a} / 10$ & 0,75 & & 16 & 600 & & 30 \\
\hline & & VIII & $20 a / 11$ & 0,5 & & 18 & 1000 & & 20 \\
\hline & & $\mathrm{IX}$ & $20 \mathrm{a} / 12$ & 0,25 & & 24 & 2000 & & 10 \\
\hline VOLUMETRIA ESPECIFICA & \multicolumn{2}{|c|}{ SUJETA A ANTERIOR ORDENACIÓN VOLUMÉTRICA } & 18 & \multicolumn{6}{|c|}{ Según Plan Parcial de ordenación } \\
\hline
\end{tabular}

\begin{tabular}{|c|c|c|c|c|c|c|c|}
\hline \multirow{2}{*}{ SISTEMA DE ORDENACIÓN } & \multicolumn{3}{|c|}{ ZONIFICACIÓN } & \multicolumn{2}{|c|}{ INTENSIDAD BRUTA } & \multicolumn{2}{|c|}{ ESTÁNDARES DE CESIÓN } \\
\hline & & Subzonas & Código & $\begin{array}{c}\text { Edificabilidad } \\
\text { coef. }\end{array}$ & $\begin{array}{c}\text { Densidad } \\
\text { viv/Ha. }\end{array}$ & $\begin{array}{c}\text { viales } \\
{[\%]}\end{array}$ & $\begin{array}{l}\text { espacios verdes/ } \\
\text { dotaciones [\%] }\end{array}$ \\
\hline VOLUMETRIA ESPECIFICA & $\begin{array}{l}\text { ZONA DE DESARROLLO } \\
\text { URBANO INT. } 1\end{array}$ & 4 TIPOS & 19 & 0,8 & & 30,4 & 19,2 \\
\hline \multirow{3}{*}{ EDIFICACIÓN AISLADA } & \multirow{2}{*}{$\begin{array}{l}\text { ZONA DE DESARROLLO } \\
\text { URBANO INT. } 2 \\
\end{array}$} & TIPO I & $20 \mathrm{~b}$ & 0,6 & 58 & 25,2 & 21,6 \\
\hline & & TIPO II & $20 \mathrm{~b}$ & 0,8 & 60 & 20,8 & 19,2 \\
\hline & \multicolumn{2}{|c|}{ ZONA DE DESARROLLO OPCIONAL } & 21 & 0,48 & 30 & 12,6 & 45,4 \\
\hline
\end{tabular}

Fuente: elaboración propia a partir de la información contenida en el Plan General de Ordenación Urbana de la Entidad Municipal Metropolitana de Barcelona. 1976. Memoria del documento de aprobación definitiva, aprobado por la Comisión de Urbanismo de Barcelona, el 14 de julio de 1976

Los parámetros de intensidad aplicados a cada una de las calificaciones permitían estimar la población potencial para cada una de ellas. Las cartografías elaboradas a escala 1:5.000 permitían, además, modular las intensidades propuestas de forma pormenorizada. Sin embargo, en aquel momento sólo se disponía de datos de población real a nivel de municipio. Por este motivo, los objetivos del modelo se plantearon a nivel de "subsistemas" (Figura 3).

Figura 3. Subsistemas delimitados por el PGM CRECIMIENTO POTENCIAL DE POBLACIÓN POR SUBSISTEMAS PREVISTO EN EL PGM

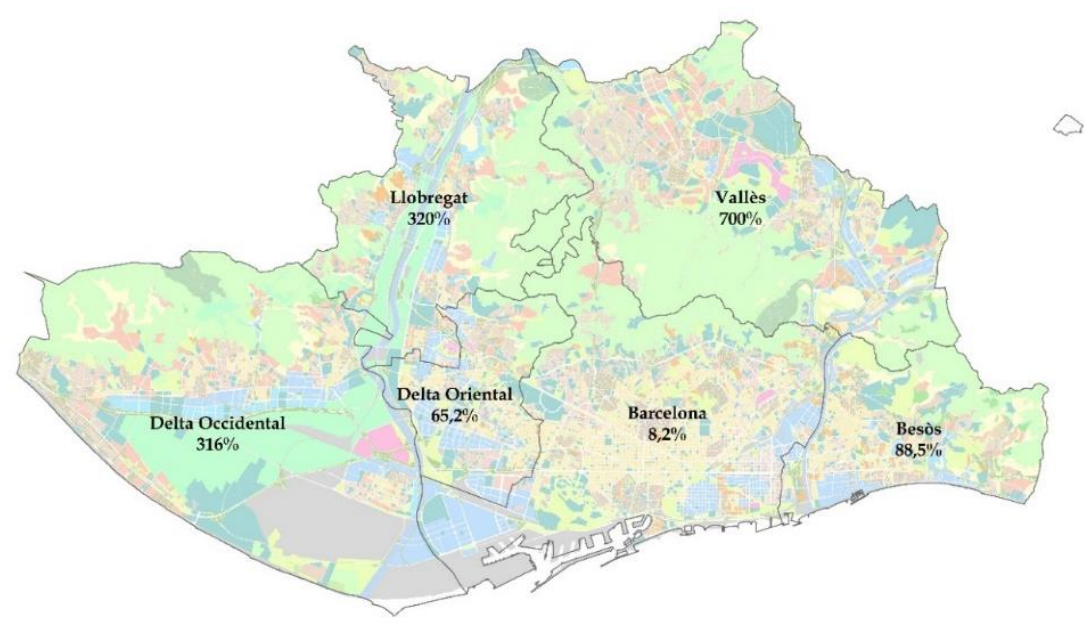

ACE, 16 (46) CC BY-ND 3.0 ES | UPC Barcelona, España | Modelizando en territorio metropolitano del futuro. 
Fuente: Plan General de Ordenación Urbana y Territorial de la Comarca de Barcelona. 1973. Memoria del documento de aprobación inicial, aprobado por la Comisión de Urbanismo de Barcelona, el 29 de marzo de 1974 y elaboración propia a partir de la restitución gráfica de las determinaciones del PGM elaborada por el AMB.

Para la estimación de la población potencial jugaba un papel relevante la cantidad de habitantes por cada vivienda. De la memoria del plan se desprende que el valor utilizado para las estimaciones de población es de 4 habitantes por vivienda.

En los suelos urbanos existentes se limitó la intensidad mediante parámetros unívocos aplicados a cada una de las calificaciones urbanísticas (Figura 2). Para no incrementar la congestión de los suelos centrales dentro del municipio de Barcelona, las calificaciones propuestas reducían las alturas máximas permitidas en relación con el anterior plan, disminuyendo así un 10\% la población potencial.

En cuanto a los suelos de desarrollo o transformación, se establecía una delimitación clara para cada uno de los sectores sobre los que se aplicaba una edificabilidad bruta máxima. Las intensidades propuestas permitían hacer frente a la demanda de vivienda sin llegar a unas densidades tan elevadas como las de la ciudad histórica o los recientes polígonos de vivienda de grandes densidades. Estas intensidades permitían a la vez generar unos beneficios suficientes para hacer atractiva la inversión teniendo en cuenta unos estándares de cesiones elevados para compensar el déficit de espacios de uso público en la ciudad consolidada.

Los mecanismos propuestos por el PGM descritos en este apartado han permitido que este plan fuera un verdadero modelo de planificación a una escala de detalle muy superior a cualquier otro plan del momento. Además, con la introducción del concepto de "subsistemas", el PGM ensayó un modelo exploratorio que se utilizó, como mínimo, para modular las intensidades entre subsistemas en el momento de su redacción. El hándicap con el que tuvo que lidiar fue la falta de base de datos de detalle suficiente para contrastar planeamiento y realidad (Solà-Morales, 1972) y la necesaria tecnología para llevarlo a cabo.

\subsection{La complejización del modelo (el Refundido de Planeamiento)}

Los mecanismos incluidos en el PGM eran consecuencia de una serie de objetivos orientados a gestionar la ordenación del conjunto del territorio metropolitano. Fueron bien comprendidos y utilizados en el desarrollo previsto por el propio plan a través de planes parciales y planes de reforma interior. Cada uno de estos planes han regulado la nueva ordenación de la edificación de manera específica y particular para el sector que estuvieran desarrollando, siempre respetando los parámetros básicos establecidos por el PGM. Además, debido a la antigüedad del plan, se han aprobado muchas modificaciones de PGM, que han alterado la regulación directa del suelo urbano consolidado en el año 1976 y también han introducido nuevos sectores de transformación que no estaban previstos inicialmente.

Las necesidades de ordenación pormenorizada de todos estos planes de desarrollo y de modificación han llevado a incluir en sus normativas gran cantidad de aspectos. En ocasiones se han incluido parámetros con un nivel de detalle tan elevado que se hace evidente su irrelevancia en el contexto de la planificación general de la metrópolis.

Como consecuencia, las 14 zonas residenciales con aprovechamiento urbanístico que definió el PGM se han transformado en más de 3.000, casi tantas como modificaciones de plan y planes de desarrollo se han aprobado (Figura 4).

La gestión de esta complejidad se pudo mantener de manera tradicional (es decir, generando planos convencionales que refundían gráficamente las diferentes modificaciones de plan y planes de desarrollo) hasta pasados unos 20 años desde la aprobación del PGM. A partir de cierto momento, la

ACE, 16 (4.6) CC BY-ND 3.0 ES | UPC Barcelona, España | Modelizando en territorio metropolitano del futuro. Cálculo de potenciales urbanísticos en la metrópolis de Barcelona. DOI: http://dx.doi.org/10.5821/ace.16.46.9883 
complejidad aumentó de tal forma que se hacía imprescindible disponer de herramientas más sofisticadas que, como mínimo, sirvieran como guía para conocer qué expedientes urbanísticos afectaban a cada punto del territorio. Cabe destacar, además, que desde la aprobación del PGM se han incorporado al AMB nueve municipios, cada uno de ellos con su propio planeamiento general.

Figura 4. Calificaciones urbanísticas con parámetros que difieren de los originales de 1976

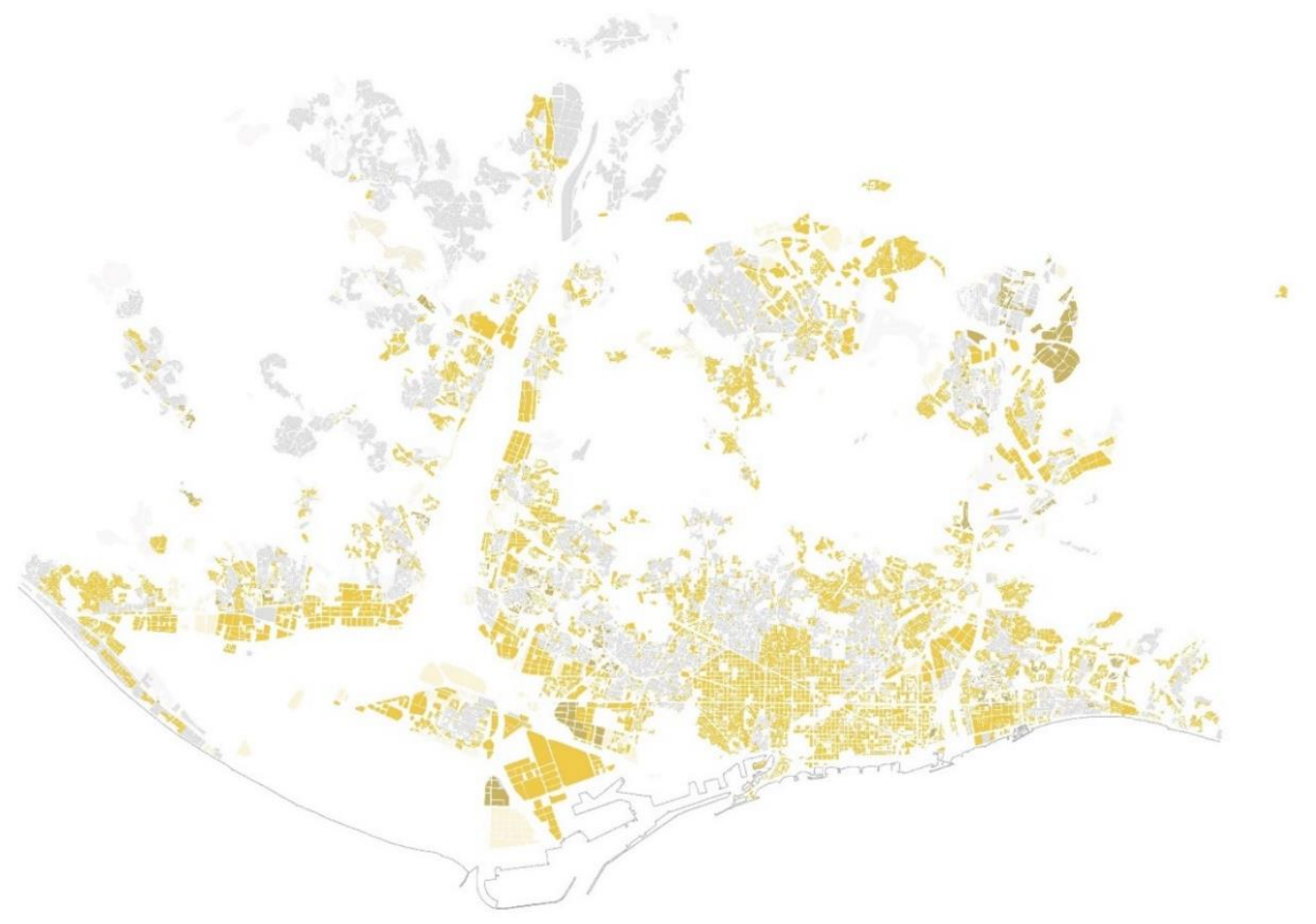

Fuente: Elaboración propia a partir del Refundido de Planeamiento del AMB

Hacia el año 2000, los servicios técnicos de urbanismo de la extinta Mancomunidad de Municipios del Área Metropolitana de Barcelona iniciaron el proyecto de extender a todos los municipios el refundido de planeamiento que ya se estaba realizando en alguno de ellos de manera convencional. La novedad fue que el proyecto se planteó, desde su inicio, como un verdadero sistema de información geográfica (SIG).

El Refundido de Planeamiento se convirtió en un documento cuya finalidad principal era la de facilitar el acceso a la información concreta de la normativa urbanística que afecta a cada punto del territorio, ofreciendo además una visión rápida y uniformizada del planeamiento urbanístico para todo el conjunto de municipios del PGM. La base de datos elaborada incorporaba los ámbitos de cada uno de los expedientes de planeamiento que desarrolla o modifica el plan, la clasificación urbanística del suelo según su nivel de desarrollo urbano, la delimitación de los sectores de desarrollo o transformación y las calificaciones urbanísticas.

El AMB ha continuado el proyecto de refundido de planeamiento de los municipios metropolitanos ${ }^{4}$. La consolidación e implementación cada vez más generalizada de los SIG permite integrar el Refundido de Planeamiento en cualquier análisis de carácter territorial que se quiera llevar a cabo.

\footnotetext{
${ }^{4}$ Ver https://geoportalplanejament.amb.cat
}

ACE, 16 (46) CC BY-ND 3.0 ES | UPC Barcelona, España | Modelizando en territorio metropolitano del futuro.

Cálculo de potenciales urbanísticos en la metrópolis de Barcelona. DOI: http://dx.doi.org/10.5821/ace.16.46.9883 


\subsection{Descripción del modelo de datos actual del Refundido de Planeamiento}

En los últimos años, para dar respuesta a las necesidades de análisis del PDU, el modelo de datos del Refundido de Planeamiento se ha ido ajustando y adaptando, discriminando los parámetros básicos para el planteo de los retos a nivel metropolitano y de aquellos que tienen una función secundaria en el marco de una reflexión global. Este enfoque hacia los parámetros básicos se ha desarrollado sin perder la referencia de los documentos urbanísticos que determinan cada una de las calificaciones para así seguir facilitando la gestión del planeamiento a nivel local.

En consecuencia, se ha dotado al Refundido de una estructura de datos con la precisión suficiente para permitir desarrollar análisis pormenorizados en base a los parámetros básicos (Figura 5).

Figura 5. Modelo de datos del Refundido de Planeamiento.

\section{MODELO DE DATOS DEL REFUNDIDO DE PLANEAMIENTO DEL AMB}

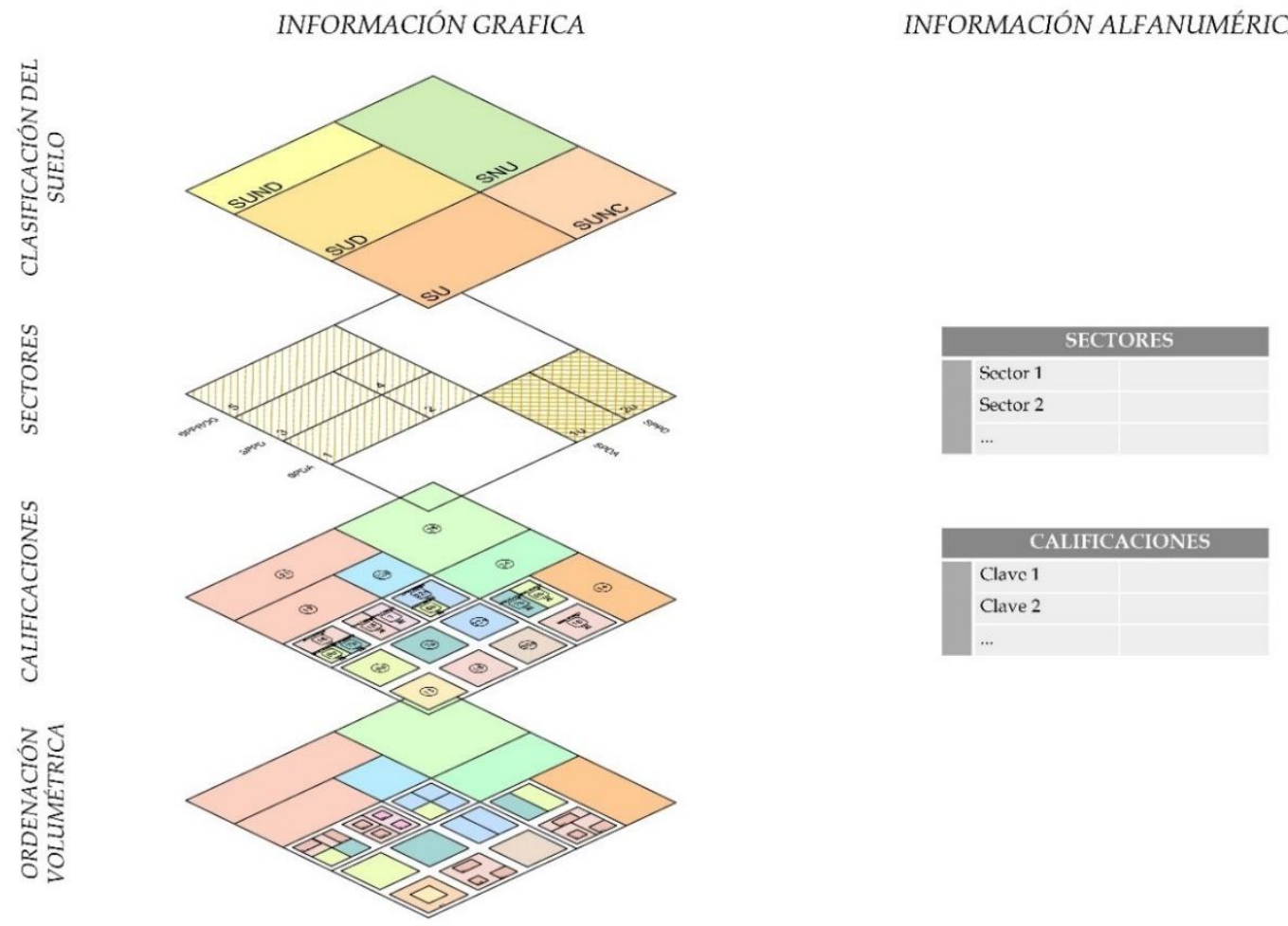

Fuente: elaboración propia a partir del Refundido de Planeamiento del AMB.

En concreto, se han incluido de forma exhaustiva para todas las calificaciones urbanísticas: el sistema de ordenación, los parámetros relevantes del mismo (ya sea de manera gráfica para el sistema de ordenación en alineación a vial, de manera alfanumérica para las edificaciones aisladas, o de manera combinada para las ordenaciones volumétricas específicas) y la distribución de la edificabilidad por usos.

El tratamiento de los distintos usos - prohibidos, permitidos o condicionados- también ha significado una considerable complejización del sistema. En primer lugar, del mismo modo que sucede con los demás parámetros, en la mayoría de los casos la regulación de los usos es específica para cada

ACE, 16 (46) CC BY-ND 3.0 ES | UPC Barcelona, España | Modelizando en territorio metropolitano del futuro. Cálculo de potenciales urbanísticos en la metrópolis de Barcelona. DOI: http://dx.doi.org/10.5821/ace.16.46.9883 
nueva calificación. Además, con el paso del tiempo, cada vez son más los expedientes de planeamiento que modifican las definiciones de cada uno de los usos para permitir una mayor flexibilidad en su gestión.

La labor de síntesis y estructuración del Refundido de Planeamiento ha contribuido a reflexionar sobre la evolución del modelo de planificación del PGM hacia los retos que ahora debe afrontar el PDU.

\subsection{Modelo PDU}

El PDU es un instrumento de regulación de escala intermedia, entre el Planeamiento territorial y el PGM, cuyo objetivo es revisar y definir la estructura metropolitana desde una visión global e integradora. Pretende facilitar las condiciones urbanísticas necesarias para dar respuesta a los retos y necesidades de la realidad social, económica y ambiental de la metrópolis actual. Representa una oportunidad para dar respuesta a los principios y valores de la sociedad actual que demanda una metrópolis saludable, democrática, equitativa y socialmente justa.

Estos objetivos e intenciones se deben traducir espacialmente en un modelo de desarrollo urbanístico metropolitano respetuoso con las capacidades del territorio. La intervención en un territorio totalmente consolidado, donde los recursos de suelo son limitados, y con un parque edificado envejecido, implica que la transformación urbana tendrá un papel relevante. Por esto, se hace necesario un análisis y diagnosis exhaustiva de la realidad existente, donde los datos toman el protagonismo y el uso de las nuevas tecnologías devienen una herramienta esencial.

La creación de modelos descriptivos han sido claves para los primeros análisis de la realidad existente. En este sentido, destacan algunos estudios ya publicados en los que se ha llegado a un detalle muy preciso en el uso de los datos de partida. Algunos han dado pie a la elaboración de indicadores, actualizables en el tiempo, que pueden ayudar en la toma de decisiones.

EL PDU se constituirá como un modelo de planificación que regulará los usos del territorio, asignando sus intensidades y determinando los estándares. Ahora bien, el tiempo y esfuerzo dedicados a la elaboración de modelos descriptivos y la síntesis que se ha realizado en algunos de ellos en forma de indicadores está permitiendo crear un borrador de lo que se podría considerar un modelo exploratorio aplicado al planeamiento.

Este modelo consistiría en la creación de un mecanismo urbanístico que contemplaría la evaluación continua de las propuestas y transformaciones urbanas propuestas por propio PDU y de los futuros planes que lo desarrollen.

La clave para poder considerar el PDU como un borrador de un modelo exploratorio aplicado al planeamiento reside en la posibilidad de disponer del Refundido de Planeamiento. La introducción de variantes en el refundido permite explorar nuevas realidades de planeamiento a considerar por el PDU, que pueden ser contrastadas con la realidad existente.

El modelo podría aplicarse a dos escalas: dando soporte en la búsqueda del equilibrio en las relaciones funcionales del territorio, a escala de subsistema, y permitiendo simular las consecuencias directas de las propuestas de ordenación sobre la movilidad, el medio ambiente y las dotaciones socioambientales, a escala local. 
El análisis del modelo actual del Refundido de planeamiento en relación con los tejidos urbanos permite disponer de información cuantitativa, con respecto a las intensidades edificatorias, así como las reservas de suelo disponibles para dotaciones y socioambientales.

Ahora bien, la explotación de los datos con una determinada intención permitirá, por un lado, explorar las propuestas del modelo operacional a realidades más concretas: contextos específicos para cada municipio o cada parte del tejido según sus particularidades físicas, morfológicas y sociales, más allá de una forma urbana genérica, y por otro, establecer mecanismos para evaluar las dotaciones socioambientales, más allá de los estándares mínimos cuantitativos establecidos por la legislación vigente, a partir de estándares cualitativos que garanticen una correcta distribución territorial, teniendo en cuenta variables de proximidad a dichas dotaciones, la capacidad de éstas, así como la evolución de la población usuaria (Anejo 8, Avance PDU, 2019).

Para garantizar un desarrollo sostenible, será necesario incluir en el modelo operacional otras variables que modularán las posibilidades de crecimiento, como puede ser: el nivel de accesibilidad al transporte público (Anejo 2, Avance PDU, 2019), planificando los desarrollos urbanos allí donde hay mayor nivel de accesibilidad, promoviendo una movilidad sostenible; los recursos disponibles, garantizando que los sistemas actuales serán capaces de proveer a los nuevos crecimientos, o prever las reservas necesarias para albergar nuevos servicios técnicos; o bien la mixtura y complejidad urbana, característica fundamental para potenciar la movilidad activa. Todas estas variables suponen condicionantes que enriquecen y complejizan el modelo, que a su vez permite adaptarse a las necesidades dinámicas y cambiantes de la sociedad actual.

Para este propósito es necesario disponer de datos precisos, completos, actualizables, coherentes, accesibles y fiables de la realidad. En este sentido, el AMB también está dedicando muchos esfuerzos a crear nuevas bases de datos que, a partir de otras existentes, se adaptan para que sean útiles y relevantes para la propuesta de un modelo exploratorio aplicado al planeamiento.

Figura 6. Bases de datos y su uso en modelos descriptivos y exploratorios.

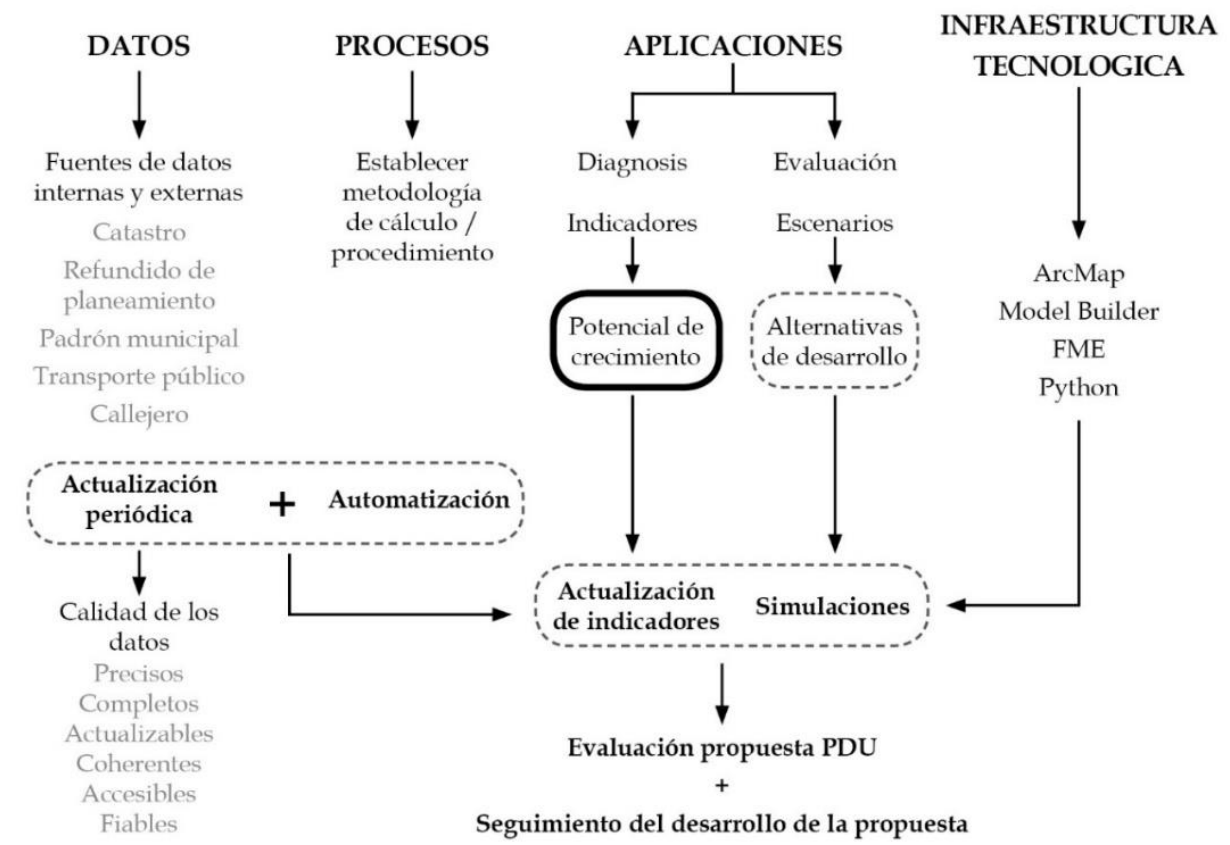

Fuente: Elaboración propia

ACE, 16 (46) CC BY-ND 3.0 ES | UPC Barcelona, España | Modelizando en territorio metropolitano del futuro.

Cálculo de potenciales urbanísticos en la metrópolis de Barcelona. DOI: http://dx.doi.org/10.5821/ace.16.46.9883 
La Figura 6 pretende esquematizar las relaciones entre las bases de datos y su uso en los modelos descriptivos y exploratorios.

El trabajo que se presenta en el siguiente capítulo es un ejemplo representativo de una herramienta urbanística que pretende configurarse como un modelo exploratorio aplicado al planeamiento. Representa el punto de partida para explorar las propuestas de crecimiento, haciendo una comparativa entre éstas y la realidad existente.

\section{Cálculo del potencial de crecimiento urbano}

Conocer el potencial de crecimiento urbano del territorio metropolitano permitido por el planeamiento vigente es una tarea imprescindible para abordar el PDU. Esta tarea resulta compleja debido a la idiosincrasia de dicho planeamiento y la dificultad de trabajar con las diferentes fuentes de datos disponibles.

Con la premisa de que uno de los retos del PDU consiste en modelar los futuros desarrollos urbanos de la metrópolis, se ha diseñado una metodología para el cálculo de este potencial. Este cálculo posibilita cuantificar el potencial según el planeamiento urbanístico vigente y también asienta las bases para la simulación de los posibles escenarios de crecimiento del PDU.

Esta sección se estructura en seis apartados que tienen por objetivo definir los conceptos clave que intervienen en la metodología de cálculo (3.1), describir las fuentes de información utilizadas (3.2), explicar las finalidades del cálculo (3.3), detallar la metodología diseñada (3.4), mostrar el modelo resultante (3.5) y exponer la aplicación de simulación de escenarios de desarrollo urbanístico futuros (3.6).

\subsection{Definiciones}

El potencial de crecimiento urbano permitido por el planeamiento vigente se define de forma genérica como la diferencia entre aquello permitido por el planeamiento urbanístico y aquello existente, sea cual sea la unidad de medida. Así, el techo potencial de actividad es la diferencia entre el techo destinado a actividades que permite el planeamiento vigente y el techo destinado a actividades en las construcciones existentes; y viviendas potenciales es la diferencia entre el número de viviendas permitidas por el planeamiento vigente y las viviendas construidas existentes.

En ciertos casos se da la casuística de que la cantidad "de aquello existente" supera la cantidad de "aquello permitido por el planeamiento vigente": nos encontramos ante las situaciones de volumetría disconforme o fuera de ordenación descritas por la ley de urbanismo (Figura 7).

Las unidades territoriales son las delimitaciones que actúan como contenedores de datos. En este sentido, el abanico de unidades territoriales es muy amplio: parcela, manzana, sección censal, municipio, el área metropolitana de Barcelona, entre muchas otras posibles. En función del objetivo, será necesario disponer del potencial asignado a una unidad territorial más o menos agregada. Para ello, la metodología de cálculo se plantea desde la unidad mínima de planeamiento, la unidad de zona, definida como toda superficie homogéneamente calificada por el planeamiento, delimitada por suelos de diferente calificación urbanística e individualizada por una misma área de referencia (art. 64 de las normas urbanísticas del PGM). Esta unidad mínima permite la agregación necesaria en cada momento.

ACE, 16 (46) CC BY-ND 3.0 ES | UPC Barcelona, España | Modelizando en territorio metropolitano del futuro. Cálculo de potenciales urbanísticos en la metrópolis de Barcelona. DOI: http://dx.doi.org/10.5821/ace.16.46.9883 

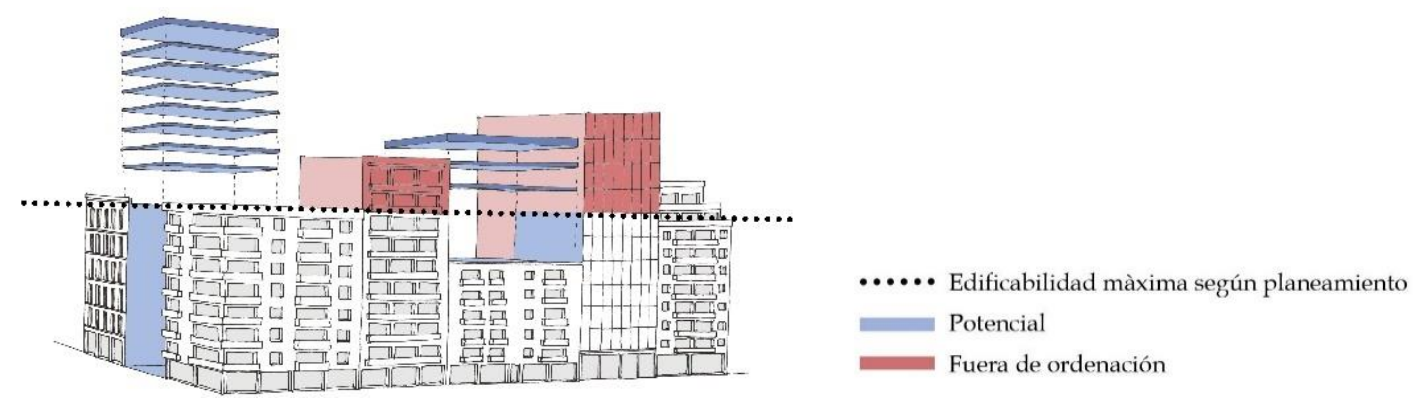

Fuente: Elaboración propia

Los modelos de residir en la metrópolis (Avance PDU, 2019), es un concepto que nace del análisis funcional de los tejidos residenciales existentes. En la metodología de cálculo, estos modelos se utilizarán para matizar ciertas ratios genéricas, relativas a la intensidad física y funcional, en base a la localización del potencial en el territorio.

Así, se distinguen tres modelos de residir diferentes en la metrópolis: el modelo de "ciudades en continuidad con la plana" agrupa los municipios de las grandes ciudades metropolitanas, que conforman un continuo urbano; el modelo de "ciudades nodales entrelazadas" agrupa los municipios de ciudades medianas del Vallès, la Vall Baixa, el Delta del Llobregat i el Baix Maresme, separadas entre sí por espacios abiertos o infraestructuras y unidas por carreteras históricas; y el modelo de "paisajes de baja densidad" agrupa los municipios en los que predominan las áreas residenciales de baja densidad, en el Ordal, Collserola y la cordillera de Marina.

\subsection{Fuentes de información}

En la metodología de cálculo del potencial intervienen dos fuentes de información: por una parte "aquello que permite el planeamiento urbanístico vigente" se obtiene de la explotación de la base de datos del Refundido de Planeamiento; por otra parte, "aquello existente"se obtiene de la explotación de la base de datos del catastro.

El Refundido de Planeamiento proporciona la información de planeamiento a nivel de unidad de zona en el suelo urbano consolidado y a nivel de sector en suelo urbano no consolidado o urbanizable. En ambos niveles de información, el dato más relevante es el techo edificable y los usos admitidos.

El catastro proporciona información sobre la ciudad existente, a nivel de parcela. Es la mejor base de datos cartográfica de la que disponemos para la modelización de la ciudad existente debido a que, aunque no destaca por su exactitud geodésica ya que es una cartografía pensada con fines fiscales, se fundamenta en el techo construido y sus usos, parámetros en común con la modelización del planeamiento.

En algunos casos será necesario armonizar los datos que provienen del refundido con los datos del catastro. Este proceso de armonización se explicitará en el cuarto apartado.

En el siguiente cuadro (Figura 8) se especifican las bases de datos que intervienen en el cálculo, detallando la unidad territorial mínima y la información disponible en cuanto a gestión y edificabilidad.

Figura 8. Fuentes de información, unidad territorial mínima e información disponible.

ACE, 16 (46) CC BY-ND 3.0 ES | UPC Barcelona, España | Modelizando en territorio metropolitano del futuro. Cálculo de potenciales urbanísticos en la metrópolis de Barcelona. DOI: http://dx.doi.org/10.5821/ace.16.46.9883 


\begin{tabular}{|c|c|c|c|c|}
\hline \multicolumn{2}{|c|}{ FUENTES DE INFORMACIÓN } & \multicolumn{3}{|c|}{ INFORMACIÓN DISPONIBLE } \\
\hline Nombre & $\begin{array}{l}\text { Mínima unidad } \\
\text { territorial disponible }\end{array}$ & Gestión & Techo & $\begin{array}{l}\text { Unidad } \\
\text { gráfica }\end{array}$ \\
\hline $\begin{array}{l}\text { Refundido: } \\
\text { Unidades de } \\
\text { zona }\end{array}$ & $\begin{array}{l}\text { Unidad de } \\
\text { zona }\end{array}$ & $\begin{array}{l}\text { Ninguna } \\
\text { (todo es suelo } \\
\text { urbano consolidado) }\end{array}$ & Techo máximo*/usos** & \\
\hline $\begin{array}{l}\text { Refundido: } \\
\text { sectores } \\
\text { urbanísticos }\end{array}$ & $\begin{array}{l}\text { Sector } \\
\text { urbanístico }\end{array}$ & $\begin{array}{l}\text { S.U.N.C } \\
\text { S.U.D } \\
\text { S.U.N.D }\end{array}$ & Techo máximo/usos & $=$ \\
\hline Catastro & Parcela & $\begin{array}{l}\text { Solar edificado } \\
\text { Solar sin edificar }\end{array}$ & Techo construido/usos & 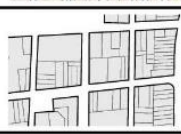 \\
\hline
\end{tabular}

* En base a un cálculo efectuado a posteriori

** En base a una estimación efectuada a posteriori

Fuente: Elaboración propia a partir del Refundido de Planeamiento del AMB y de la cartografía catastral.

\subsection{Finalidades del cálculo}

Todas las utilidades que derivan de este cálculo deben entenderse desde la doble vertiente del conocimiento del potencial actual y de un potencial que vendrá definido por las futuras determinaciones urbanísticas del PDU.

Las principales finalidades de conocer el potencial son la de evaluar los límites del territorio espacial y temporalmente, y la de someter a una visión crítica ciertos mecanismos de planeamiento.

Cabe remarcar que nos encontramos ante un territorio muy consolidado, con una capacidad de crecimiento limitada, en que la necesidad de cuantificar aquello que es posible crecer mediante el agotamiento del planeamiento vigente deviene imprescindible para poder evaluar su oportunidad o inconveniencia. Esta cuantificación requiere una buena localización espacial y temporal de las potencialidades.

Con este fin, la metodología de cálculo integra dos variables: la espacial, introduciendo las unidades territoriales como mecanismo para hacer efectivo el cálculo del potencial distribuido en el territorio; y la temporal, considerando el estado fáctico del suelo en relación con la clase de suelo, la tramitación del planeamiento urbanístico correspondiente o el desarrollo de la gestión urbanística pendiente.

Hay que señalar que más allá de la evaluación de los límites que supone alcanzar el potencial previsto actualmente, el hecho de cuantificar este potencial es condición necesaria para poder establecer estrategias en aspectos como el techo existente no conforme con el planeamiento urbanístico vigente o la relación entre los parámetros urbanísticos y los modelos de asentamientos existentes.

\subsection{Metodología de cálculo}

La metodología utilizada para el cálculo del potencial se puede dividir en 3 fases: el trabajo sobre las fuentes de información, el cálculo de techo por unidades territoriales mínimas y la transformación de los resultados en valores interpretables.

Figura 9. Fases de la metodología de cálculo. 


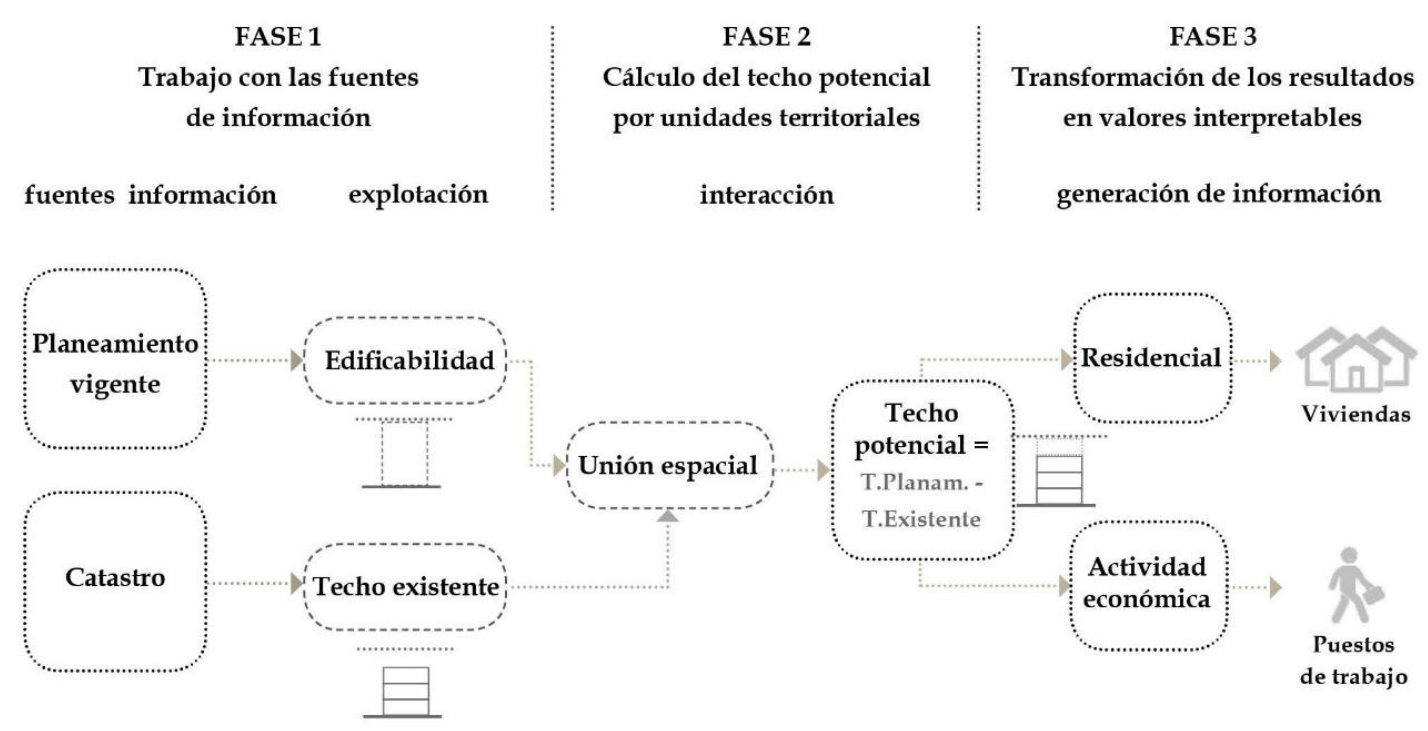

Fuente: Elaboración propia.

FASE 1: trabajo con las fuentes de información

Del catastro obtenemos la información del techo edificado sobre rasante y los usos que lo componen, a partir de la tabla del registro 14 (registro de construcción), georreferenciada con la información de localización de las parcelas catastrales.

El Refundido de Planeamiento permite la explotación de datos a través de la unidad de zona en el suelo urbano consolidado y a través de los sectores para los territorios clasificados como suelo urbano no consolidado o urbanizable. Pero los datos asociados a las unidades de zona no disponen siempre de la información de techo y del porcentaje de techo que se destina a cada uso de forma directa.

Es estos casos, la previsión del techo edificable se calcula en función de otros parámetros basados en la información relativa al sistema de ordenación al que corresponden:

- En ordenación de alineación a vial, el techo edificable se obtiene de multiplicar el área edificable de planeamiento (perímetro por profundidad edificable) por el número máximo de plantas admisible.

- En ordenación por volumetría específica, el techo edificable se define por cada una de las unidades de proyecto. En aquellos casos en los que no se dispone de la información necesaria para la obtención de la edificabilidad, se asimila como dato de planeamiento el techo construido según datos del catastro.

- En ordenación de edificaciones aisladas, el techo edificable se obtiene de multiplicar la unidad de zona por el índice de edificabilidad neta correspondiente.

La estimación del porcentaje de techo que se destina a cada uso se aplicará sobre el techo potencial residencial, atendiendo a la mixtura de usos que se da en los tejidos residenciales plurifamiliares. El cálculo también depende del sistema de ordenación, con alguna variación:

- En ordenación de alineación a vial, con carácter general, se destinan las plantas bajas a usos comerciales y parte del techo de las plantas piso (a veces entresuelos y/o primeras plantas) a usos de oficina. Así pues, se ha analizado el porcentaje de techo destinado a usos de actividad económica en las edificaciones alineadas a vial existentes, según los datos del catastro, en los tres modelos de residir explicados anteriormente. En base a este análisis, se

ACE, 16 (46) CC BY-ND 3.0 ES | UPC Barcelona, España | Modelizando en territorio metropolitano del futuro. 
prevé un porcentaje de techo destinado a usos no residenciales (de actividad) para cada unidad de zona, determinado según el modelo de residir en el que se localiza: 20\% en el modelo "ciudades en continuidad", 15\% en el modelo "ciudades nodales entrelazadas" y 10\% en el modelo "paisajes de baja densidad".

- En ordenación por volumetría específica y en ordenación de edificaciones aisladas de carácter residencial plurifamiliar, se ha utilizado el mismo método, siempre y cuando el planeamiento no especifique de manera concreta la distribución de usos y así lo haya recogido el Refundido de Planeamiento.

- En ordenación de edificaciones aisladas de carácter unifamiliar o de uso exclusivo industrial, el techo resultante del cálculo se asigna en su totalidad a uso residencial o de actividad, respectivamente.

FASE 2: Cálculo del techo potencial por unidades territoriales

Para el cálculo del potencial es esencial cruzar la información de planeamiento con los datos de catastro.

Las fuentes de datos que utilizamos, como se ha señalado, destacan por el nivel de desagregación de los datos. Por ese motivo se ha trabajado para obtener una relación directa entre los elementos urbanísticos y la parcela urbana. Esta aproximación será de utilidad para la aplicación de mecanismos de "cirugía de detalle" que requerirá el desarrollo urbano futuro orientado hacia el suelo urbano consolidado.

Comparar planeamiento y catastro implica poner en consonancia las unidades territoriales mínimas de información de cada una de las bases: las unidades de zona y sectores, y las parcelas, entre las cuales no siempre existe una correspondencia geométrica.

La metodología propuesta permite asociar la información de las dos bases, asignando el resultado del cálculo del techo potencial a la unidad territorial mínima de planeamiento (unidad de zona o sector), en tanto que unidades territoriales de carácter urbanístico. Así pues, estas unidades territoriales actúan como contenedores de parcelas, agrupando todas las que se superponen con dicha unidad de zona o sector (Figura 10). Las parcelas que se localizan a caballo entre dos unidades de zona se asignan a aquella con la que comparten más superficie.

Así, el potencial permitido por el planeamiento vigente (P) queda definido como:

$\boldsymbol{P}=\sum_{i=1}^{n}\left(\boldsymbol{P}_{\boldsymbol{i}}\right)$

Tal que,

$\boldsymbol{P}_{\boldsymbol{i}}$ es el potencial concreto de una unidad territorial i concreta de las $n$ unidades territoriales del AMB (unidades de zona y sectores), que queda definido como:

$\boldsymbol{P}_{\boldsymbol{i}}=\boldsymbol{P} \boldsymbol{p}_{\boldsymbol{i}}-\boldsymbol{E} \boldsymbol{x}_{\boldsymbol{i}}$, siendo:

$\boldsymbol{P} \boldsymbol{p}_{\boldsymbol{i}}$ el techo/viviendas/actividades revisto por el planeamiento vigente en una unidad territorial (unidad de zona o sector) i concreta, y

$\boldsymbol{E} \boldsymbol{x}_{\boldsymbol{i}}$ el techo/viviendas/actividades existentes (real) calculado a través del catastro en una unidad territorial (unidad de zona o sector) i concreta.

ACE, 16 (46) CC BY-ND 3.0 ES | UPC Barcelona, España | Modelizando en territorio metropolitano del futuro. Cálculo de potenciales urbanísticos en la metrópolis de Barcelona. DOI: http://dx.doi.org/10.5821/ace.16.46.9883 


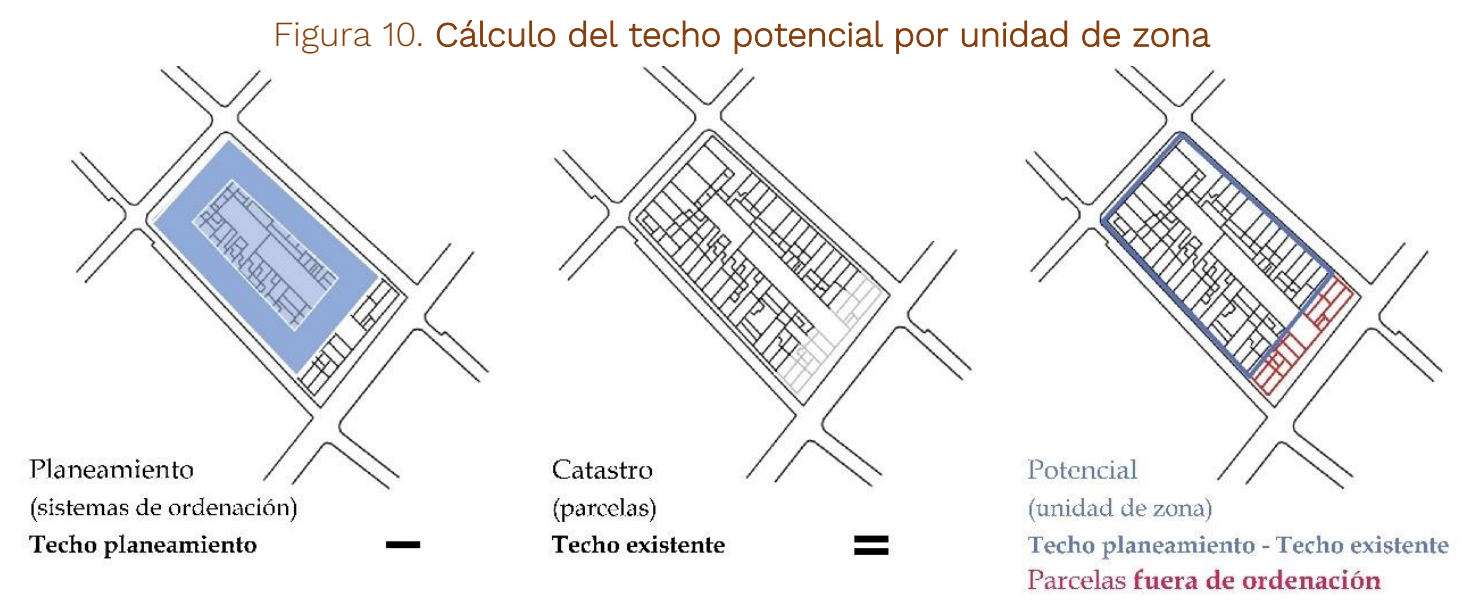

Fuente: Elaboración propia a partir del Refundido de Planeamiento del AMB y de la cartografía catastral.

Es preciso señalar que los datos referidos a techo que provee el catastro están vinculados gráficamente a nivel de parcela, no a nivel de construcción. Por este motivo, ante la falta de información sobre la disposición concreta de la edificación en la parcela y sobre la afectación de las determinaciones urbanísticas de esta disposición concreta de la edificación, no es posible localizar el techo existente reconocido por el planeamiento y el techo existente fuera de ordenación o en volumetría disconforme.

Además, cabe remarcar que la elección de la unidad territorial a la que se asigna el potencial tiene fuertes implicaciones en el cálculo de éste, en tanto que como mayor sea la unidad territorial, mayor es la incertidumbre en el cálculo de las edificaciones existentes en situación "fuera de ordenación" y/o "volumetría disconforme" (Anejo 7, Avance PDU, 2019). El cálculo y asignación del potencial a la unidad mínima de planeamiento reduce al máximo las posibles distorsiones.

FASE 3: Transformación de los resultados en valores interpretables (viviendas, actividades, lugares de trabajo, etc.)

El interés del cálculo del techo potencial, entre otras finalidades, es el de su traducción a unidades más tangibles, como el número de viviendas potenciales y lugares de trabajo generados por la actividad económica.

Este dato será de gran utilidad para regular el equilibrio entre las funciones del territorio, residir y trabajar, que inciden de forma directa en el día a día de las personas, la movilidad y sus externalidades derivadas.

El techo potencial puede ser traducido en función de las variables que sean requeridas. A continuación, se explican las ratios consideradas en el cálculo realizado para el avance del PDU:

- Traducción del techo potencial residencial a viviendas

Para el techo potencial residencial plurifamiliar se aplica una ratio de tamaño de vivienda. Ésta se define en función del modelo de residir en que se localiza el potencial, a partir del tamaño de vivienda media en cada uno de estos modelos, determinado según los datos de catastro. Las ratios son: $80 \mathrm{~m}^{2} / \mathrm{vivienda}$ en el modelo "ciudades en continuidad", $100 \mathrm{~m}^{2} /$ vivienda en el modelo "ciudades nodales entrelazadas" y $150 \mathrm{~m}^{2} /$ vivienda en el modelo "paisajes de baja densidad".

ACE, 16 (46) CC BY-ND 3.0 ES | UPC Barcelona, España | Modelizando en territorio metropolitano del futuro. 
Son excepción las zonas urbanísticas residenciales unifamiliares, en las que se sigue otro método. En estas zonas, se detecta que la cuantificación del techo potencial es muy elevada. Este techo responde principalmente a parcelas que no han agotado su edificabilidad según planeamiento vigente (techo que solo se podría materializar con una ampliación de la propia vivienda) y a parcelas vacías. En estos casos el número de viviendas potenciales se asimilan a las parcelas vacías contabilizadas.

En los sectores de planeamiento que prevén usos residenciales, cuando el planeamiento especifica el número de viviendas máximo permitido, se toma este dato. Cuando no se especifica, se utiliza el dato de techo residencial máximo admisible que especifica el planeamiento, dividido por la ratio correspondiente según el modelo de residir en el que se localiza el sector.

- Traducción del techo potencial de actividad a puestos de trabajo

Para la traducción del techo potencial a puestos de trabajo se proponen unas ratios de techo en función del tipo de actividad. Estas ratios parten del estudio Estimación y comparación de la población ocupada residente y los lugares de trabajo localizados en los municipios de la provincia de Barcelona (Anejo 6, Avance PDU, 2019), que hace una estimación de $\mathrm{m}^{2}$ de techo existente de cada tipo de actividad (según catastro), así como del número de trabajadores afiliados a cada uso, para generar la ratio de $\mathrm{m}^{2}$ por trabajador.

Para la presente metodología, las distintas actividades del estudio se agrupan en las tres categorías (Figura 11) que definen las actividades según planeamiento (industrial, terciaria y equipamiento) y para cada categoría se calcula la ratio ponderada de $\mathrm{m}^{2}$ por trabajador, en función de la intensidad de uso de las actividades de catastro que se equiparan a esta.

Figura 11. Relación entre actividades de catastro y actividades de planeamiento

\begin{tabular}{c|l|l|l} 
& Agropecuario & Oficinas & Religioso \\
$\begin{array}{c}\text { ACTIVIDADES } \\
\text { CATASTRO }\end{array}$ & Construcción & Hosteleria & Sanitario y social \\
& $\begin{array}{l}\text { Energía, agua, saneamiento } \\
\text { Extractivas }\end{array}$ & Educación \\
& Transporte y almacenamiento & & Deportivo \\
\hline ACTIVIDADES & Industrial & Terciario & Equipamientos \\
PLANEAMIENTO & & &
\end{tabular}

Fuente: elaboración propia

\subsection{Resultados}

Se ha automatizado el proceso de cálculo con el propósito de agilizar y poder reproducir cuantas veces sea necesario el método expuesto. El resultado de ejecutar este proceso es una base de datos que comprende la información de las intensidades físicas y funcionales existentes y las que establece el planeamiento vigente, así como el potencial que deriva de ellas (en techo y su traducción a viviendas y puestos de trabajo). Estos datos están georreferenciados en base a las unidades de zona y sectores de planeamiento.

Más allá del análisis o valoración cuantitativa de los resultados numéricos obtenidos, que no es objeto de esta comun1icación, los resultados deben leerse desde dos ópticas: por un lado, el interés de la información relativa al potencial y, por otro lado, el avance en la construcción del modelo PDU.

En primer lugar, el modelo generado facilita una lectura detallada de las capacidades de crecimiento actual del territorio. La herramienta de cálculo permite detectar los desajustes entre la realidad

ACE, 16 (46) CC BY-ND 3.0 ES | UPC Barcelona, España | Modelizando en territorio metropolitano del futuro. 
construida y el planeamiento vigente, localizando en el territorio las posibilidades de crecimiento y el techo no conforme con el planeamiento vigente (Figura 12). En este sentido, este modelo dispone de la información necesaria para iniciar un estudio en profundidad sobre la valoración del desarrollo de las previsiones del PGM.

Figura 12. Fragmento del mapa de techo potencial según planeamiento vigente del AMB, elaborado a partir de los resultados obtenidos con la herramienta de cálculo

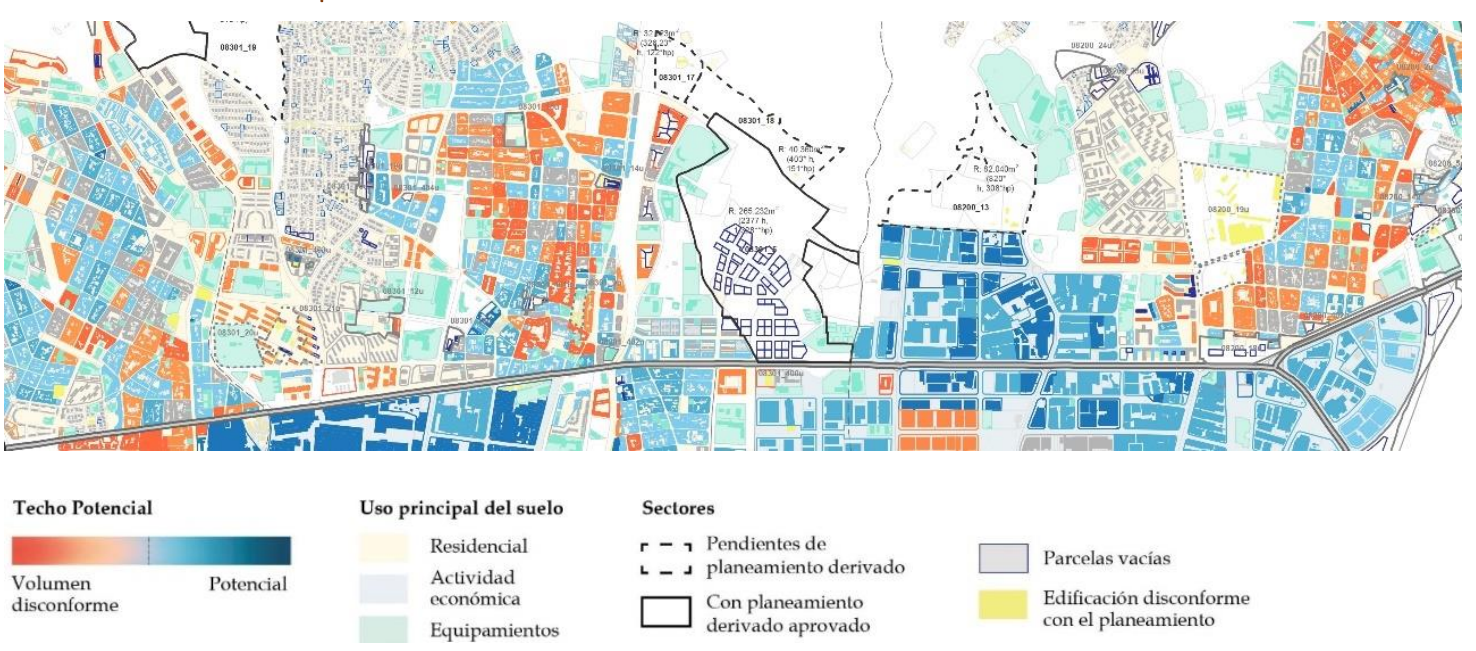

Fuente: elaboración propia a partir de la información catastral y del Refundido de Planeamiento del AMB

En segundo lugar, la cuantificación del potencial de crecimiento urbano deviene esencial para el análisis y valoración de la demanda de movilidad futura, del ajuste o desajuste en materia de vivienda protegida entre territorios y de la demanda de nuevos servicios y dotaciones socioambientales (equipamientos, zonas verdes, energía, agua), etc. En este sentido, la posibilidad de agregación de la información en unidades territoriales de escala intermedia (como pueden ser los tejidos residenciales o de actividad económica, los municipios o los subsistemas) facilita el proceso de abstracción en la lectura de los datos, necesario para abordar la toma de decisiones en la búsqueda de equilibrio en las relaciones funcionales del territorio.

Finalmente, el hecho de disponer de la herramienta de cálculo automatizada posibilita, por una parte, la actualización periódica de los resultados en base a las nuevas versiones de las fuentes de información y, por otra parte, abre el camino hacia la simulación de diferentes escenarios de desarrollo urbanístico en función de las determinaciones urbanísticas propuestas por el PDU, como veremos en el apartado siguiente.

\subsection{Simulaciones}

Gracias a la gran cantidad de fuentes de información detallada disponibles es posible abordar cuestiones urbanas desde una óptica innovadora y dar un nuevo enfoque a la planificación con la ayuda y el potencial de las herramientas SIG y sus aplicaciones para la simulación.

La monitorización de parámetros de la herramienta de cálculo nos permite simular, analizar y evaluar diferentes alternativas de desarrollo urbanístico en función de las intensidades físicas y funcionales propuestas por el PDU, comparándolas con la realidad existente.

ACE, 16 (46) CC BY-ND 3.0 ES | UPC Barcelona, España | Modelizando en territorio metropolitano del futuro. Cálculo de potenciales urbanísticos en la metrópolis de Barcelona. DOI: http://dx.doi.org/10.5821/ace.16.46.9883 
El PDU, en su objetivo de modular los futuros crecimientos o desarrollos urbanos, definirá unas estrategias de actuación focalizadas en unos ámbitos de intervención: ámbitos de proyecto metropolitano, con el objeto de integrar las grandes infraestructuras; ámbitos de centralidad metropolitana, con el objeto de articular el territorio mediante una estructura policéntrica de nodos de atracción donde se intensifiquen servicios, actividades económicas y residenciales; ámbitos de reforma, con el objeto de regenerar, remodelar o transformar tejidos residenciales o de actividad económica; y ámbitos de extensión, donde se prevén futuros desarrollos urbanos.

En función de la estrategia de desarrollo urbanística prevista en un ámbito determinado, la herramienta de simulación ofrece la posibilidad de modificar el valor de ciertos parámetros que intervienen en el proceso de cálculo. En todos los casos, la ejecución del modelo permite simular escenarios con distintas intensidades físicas y funcionales y la traducción del techo potencial a viviendas y lugares de trabajo.

El diseño actual de la herramienta permite tres mecanismos de interacción como instrumento de simulación, que se irán ampliando o modificando en función de las estrategias de intervención definitivas el PDU. Estos mecanismos son:

- Estrategia de sustitución o nuevos crecimientos

Implica hacer tabula rasa del planeamiento existente y definir de nuevo las intensidades físicas y funcionales del ámbito. Se aplicará en ámbitos que el PDU delimite para nuevos crecimientos o extensiones, o para la transformación de la estructura urbana preexistente.

Los parámetros monitorizados para la simulación son: el índice de edificabilidad bruta del ámbito, el reparto porcentual del techo planeado por usos (residencial, industrial, terciario y equipamientos), el tamaño de las viviendas y la ratio de $\mathrm{m}^{2}$ de techo por trabajador, que se traduce en puestos de trabajo (ofreciendo la posibilidad de introducir valores distintos según el tipo de actividad).

- Estrategia de variación de la densidad y edificabilidad

Implica la modificación de los parámetros que influyen en la edificabilidad de los sistemas de ordenación alineados a vial y edificaciones aisladas. Esta estrategia se aplicará en los ámbitos que el PDU define como elementos de intensificación (como las avenidas y centralidades metropolitanas) y en ámbitos de reforma.

Los parámetros monitorizados para la simulación son: el número de plantas en las edificaciones alineadas a vial, el índice de edificabilidad en las edificaciones aisladas y, igual que en el caso anterior, el tamaño de las viviendas y la ratio de $\mathrm{m}^{2}$ de techo por trabajador.

- Estrategia de densificación

Se trata de una estrategia con afectación a las edificaciones aisladas unifamiliares, donde según planeamiento vigente solo se permite una vivienda, por norma general. Esta simulación implica la transformación de las zonas de ordenación en edificación aislada unifamiliar a plurifamiliar, hecho que implica un incremento del índice de edificabilidad y de la densidad de viviendas.

En la Figura 13 se resumen principales características de las tres estrategias descritas:

Figura 13. Mecanismos para la simulación de escenarios PDU 


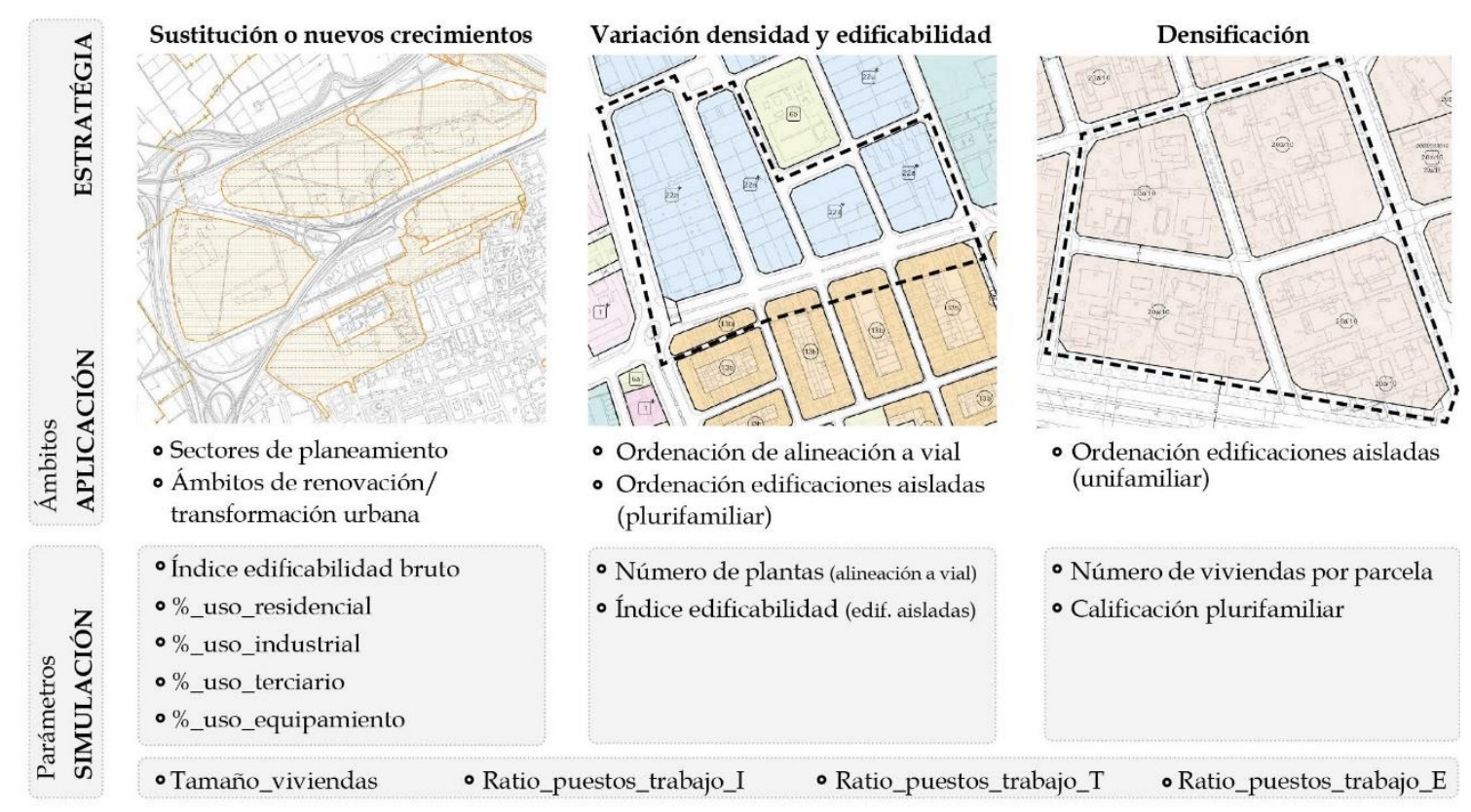

Fuente: elaboración propia a partir del Refundido de Planeamiento del AMB

\section{Conclusiones}

Los modelos exploratorios conocidos, y que trabajan sobre el territorio del área metropolitana de Barcelona, incluyen propuestas de planeamiento (ya sean propuestas de infraestructuras o de ocupación del suelo), como un factor de interacción con el modelo, pero ello sin alterar la filosofía del modelo exploratorio.

El PGM se constituyó como un verdadero modelo de planificación a una escala de detalle muy superior a cualquier otro plan del momento. Además, ensayó un modelo exploratorio que se utilizó, como mínimo, para modular las intensidades entre subsistemas en el momento de su redacción. El hándicap con el que tuvo que lidiar fue la falta de base de datos de detalle suficiente para contrastar planeamiento y realidad y la necesaria tecnología para llevarlo a cabo.

Hoy en día, la tecnología permite analizar bastas y complejas bases de datos. Además, el AMB ha creado y mantiene una base de datos específica -el Refundido de Planeamiento- que contiene los modelos de planeamiento vigentes.

EL PDU se constituirá como un modelo de planificación: regulará los usos del territorio, asignando sus intensidades y determinando los estándares. Ahora bien, el tiempo y esfuerzo dedicados a la elaboración de modelos descriptivos y la síntesis que se ha realizado en algunos de ellos en forma de indicadores está permitiendo crear un borrador de lo que se podría considerar un modelo exploratorio aplicado al planeamiento.

La herramienta de cálculo del techo potencial elaborada en el contexto del PDU se configura como un mecanismo esencial para la evaluación de aspectos tan dispares como la valoración de la demanda de movilidad futura, el ajuste o desajuste en materia de vivienda protegida entre territorios o la demanda de nuevos servicios y dotaciones socioambientales.

ACE, 16 (46) CC BY-ND 3.0 ES | UPC Barcelona, España | Modelizando en territorio metropolitano del futuro. Cálculo de potenciales urbanísticos en la metrópolis de Barcelona. DOI: http://dx.doi.org/10.5821/ace.16.46.9883 
Esta herramienta es un primer paso hacia la construcción de un modelo exploratorio diseñado para la evaluación dinámica de las estrategias urbanas propuestas por el PDU, es decir: un modelo exploratorio aplicado al planeamiento.

En consecuencia, una vez aprobado el PDU, éste probablemente contendrá directrices o normas dependientes de un modelo exploratorio definido en el mismo documento, el mantenimiento del cual debería venir a cargo del AMB. Estas directrices o normas podrán vincular decisiones de planeamiento posterior a indicadores asociados al modelo exploratorio.

De manera más concreta, las futuras propuestas de densificación lideradas por los actores locales podrán vincularse a la efectiva comprobación de que, en los escenarios futuros, no se producen zonas de sombra en relación con los nuevos servicios y dotaciones socioambientales propuestos por el plan, o que la movilidad generada puede ser absorbida por las infraestructuras existente, o incluso si la proporción de vivienda protegida o lugares de trabajo potencialmente creados no afectan los equilibrios establecidos por el PDU.

En definitiva, la introducción de un modelo exploratorio aplicado al planeamiento permitirá dotar al sistema urbanístico del AMB de una herramienta de negociación y flexibilización, capaz de valorar diferentes alternativas de desarrollo, sin la necesidad de introducir modificaciones constantemente. Y todo ello asegurando que se cumplen los objetivos generales del plan.

\section{Autoría}

El trabajo ha sido conceptualizado y diseñado por cinco autores. El primer autor ha escrito todas las secciones excepto la 2.4 y la 3 y ha aportado la coherencia necesaria entre todas las partes. La segunda autora ha realizado el diseño de la herramienta de cálculo del techo potencial y ha escrito la sección 3. La tercera autora ha redactado la sección 2.4. Finalmente, la cuarta autora y el quinto autor han revisado y aportado las mejoras imprescindibles para su publicación.

Conflicto de intereses: Los autores declaran que no hay conflicto de intereses.

\section{Bibliografía}

Cerda Troncoso, J.F.; Romano Grullón, Y.; Pérez Prieto, C. y Roca Cladera, J. (2012). Modelo EVALÚAIMPACT, sobre la evaluación de planes y proyectos en la dimensión de eficiencia energética y ambiental del modelo EVALÚAMET. ACE: Architecture, City and Environment, 7(19), 187-216. DOI: http://dx.doi.org/10.5821/ace.v7i19.2568

Echeñique Talavera, M. (1970). Modelos: una discusión. Planificación: vivienda, ciudad, región (Santiago de Chile), 7, 89-98.

Foot, D. (1981). Operational urban models. An introduction. Londres: Methuen \& Co. Ltd.

Munizaga, G. (2014). Diseño urbano. Teoría y Método. Santiago de Chile: Ediciones Universidad Católica de Chile.

Pié, R. 1997. El projecte disciplinar: la versió de 1974 del Pla General Metropolità. Papers. Regió Metropolitana de Barcelona (Barcelona), 28, 15-41. Recuperado de https://raco.cat/index.php/PapersIERMB/article/view/102593 
Solà-Morales Rubio, M. 1969. Sobre metodología urbanística. Algunas consideraciones. Barcelona: Escuela Técnica Superior de Arquitectura de Barcelona.

Solà-Morales Rubio, M. 1972. El Área Metropolitana de Barcelona. Cuadernos de arquitectura y urbanismo (Barcelona), 87, 19-20. Recuperado de: https://raco.cat/index.php/CuadernosArquitecturaUrbanismo/article/view/111078/167002?

Pla Director Urbanístic de l'Àrea Metropolitana de Barcelona. 2019. Documento de Avance, aprobado por el Consell Metropolità de l'Àrea Metropolitana de Barcelona, el 26 de marzo de 2019. AMB (2019). Anejos 2, 6, 7 y 8 .

Plan General de Ordenación Urbana y Territorial de la Comarca de Barcelona. 1973. Documento de aprobación inicial, aprobado por la Comisión de Urbanismo de Barcelona, el 29 de marzo de 1974.

DG del Catastro 2019. Cartografía digital rústica y Urbana [online] Recuperado de http://www.catastro.minhap.gob.es/esp/productos.asp\#prod8

AMB. Planejament urbanistic refós de l'àmbit metropolità 2019 [online] Recuperado de https://geoportalplanejament.amb.cat 